\title{
Sea ice and snow thickness and physical properties of an ice floe in the western Weddell Sea and their changes during spring warming
}

\author{
Christian Haas $^{\mathrm{a}, *, 1}$, Marcel Nicolaus ${ }^{\mathrm{a}, 2}$, Sascha Willmes ${ }^{\mathrm{b}}$, Anthony Worby ${ }^{\mathrm{c}}$, David Flinspach ${ }^{\mathrm{a}}$ \\ a Alfred Wegener Institute for Polar and Marine Research, 27570 Bremerhaven, Germany \\ ${ }^{\mathrm{b}}$ Department of Climatology, University of Trier, Trier, Germany \\ ${ }^{\mathrm{c}}$ ACE CRC, Australian Antarctic Division, Hobart, Australia
}

Accepted 22 December 2007

\begin{abstract}
Helicopter-borne and ground-based electromagnetic (EM) ice thickness and ruler-stick snow thickness measurements as well as icecore analyses of ice temperature, salinity and texture were performed over a 5-week observation period between November 27, 2004, and January 2, 2005, on an ice floe in the western Weddell Sea at approximately $67^{\circ} \mathrm{S}, 55^{\circ} \mathrm{W}$. The study was part of the Ice Station Polarstern (ISPOL) expedition of German research icebreaker R.V. Polarstern, investigating changes of physical, biological, and biogeochemical properties during the spring warming as a function of atmospheric and oceanic boundary conditions. The ice floe was composed of fragments of thin and thick first-year ice and thick second-year ice, with modal total thicknesses of $1.2-1.3,2.1$, and $2.4-2.9 \mathrm{~m}$, respectively. This included modal snow thicknesses of $0.2-0.5 \mathrm{~m}$ on first-year ice and $0.75 \mathrm{~m}$ on second-year ice. During the observation period, snow thickness decreased by less than $0.2 \mathrm{~m}$. There was hardly any ice thinning. Warming of snow and ice between 0.1 and $1.9^{\circ} \mathrm{C}$ resulted in decreased ice salinity and increased brine volume. Direct current (DC) geoelectric and electromagnetic (EM) induction depth sounding were performed to study changes of electrical ice conductivity as a result of the observed ice warming. Bulk ice conductivity increased from to 37 to $97 \mathrm{mS} / \mathrm{m}$. Analysis of conductivity anisotropy showed that the horizontal ice conductivity changed from 9 to $70 \mathrm{mS} / \mathrm{m}$. These conductivity changes have only negligible effects on the thickness retrieval from EM measurements.
\end{abstract}

Crown Copyright (C) 2008 Published by Elsevier Ltd. All rights reserved.

Keywords: Weddell Sea; Sea ice and snow thickness; Ice-core analysis; Electromagnetic (EM) ice thickness profiling; EM and direct current (DC) geoelectric depth sounding; Ice conductivity

\section{Introduction}

The western Weddell Sea is one of only a few regions around Antarctica covered by perennial sea-ice, and plays thus a key role for the freshwater and energy budget of the Southern Ocean. During summer, the properties of sea-ice and snow change considerably as a result of increased heat fluxes both from atmosphere and ocean, causing a marked warming of the ice and snow and a reversal of vertical temperature gradients with higher temperatures at the

\footnotetext{
*Corresponding author at Tel.: + 17804928171 ; fax: + 17804922030 .

E-mail address: Christian.Haas@ualberta.ca (C. Haas).

${ }^{1}$ Now at Department of Earth \& Atmospheric Sciences at University of Alberta, Edmonton, Canada.

${ }^{2}$ Now at Norwegian Polar Institute, Tromsø, Norway.
}

surface than at the bottom. As a consequence, increased snow metamorphism and thinning, internal and bottom melting, and high rates of algal primary productivity are observed (e.g., Thomas et al., 1998; Haas et al., 2001; Nicolaus et al., 2006). Little is known about the atmospheric and oceanic boundary conditions of these processes in late spring and early summer. Therefore, boundary conditions and consequent changes of physicalbiological sea-ice properties were studied during a research cruise of the German research icebreaker R.V. Polarstern to the western Weddell Sea between November 2004 and January 2005. The main activity of this Ice Station Polarstern (ISPOL) expedition was meteorological, oceanographic, glaciological, biological, and biogeochemical investigations on a large ice floe during a 5-week observation period while the ship was anchored to the floe 
and drifted with the ice pack (Hellmer et al., 2006; Dieckmann et al., 2007).

As part of the basic observational programme, extensive surveys of sea-ice and snow thickness of the ISPOL floe and their changes were performed. While the main goal was observations of sea-ice and snow thinning during the 5 -week study period, together with ice-core data the surveys also were used to characterize different ice types composing the ISPOL floe, and thus provide important background information on the different study sites occupied on the floe. Earlier ice thickness observations showed that the wider region around the ISPOL floe is characterized by a mixture of first- and second-year ice floes (Lange and Eicken, 1991; Lytle and Ackley, 1996; Strass and Fahrbach, 1998). Modal total (snow plus ice) thicknesses of first-year ice type were found to range between 0.4 and $1.2 \mathrm{~m}$, while typical second-year ice modal total thicknesses ranged between 1.8 and $3.0 \mathrm{~m}$. Here, we present the results of our thickness measurements on the ISPOL floe and provide a classification of the different study sites, supported by results from ice-core salinity and texture analyses.

While drilling provides the most accurate ice and snow thickness estimates (e.g., Lange and Eicken, 1991; Eicken et al., 1994), the method is limited by its slow progress, in particular on thick second-year ice, preventing the acquisition of long profiles spanning and demarcating regions of different ice types. More importantly, based on earlier observations by Lange and Eicken (1991), Eicken et al. (1994), and Lytle and Ackley (1996), we were expecting the widespread occurrence of negative ice freeboard as a result of thick snow depressing the snow/ice interface below the seawater level. Drill holes would irreversibly cause seawater to flush onto the ice surface if the ice had not yet been flooded for natural reasons (as observed during ISPOL, see below). Or, if flooding would already had occurred before drilling, drill holes would perturb the hydraulic system and would provide pathways for the exchange of water, heat, and radiation between the ice surface and underside. In both cases the development of ice and snow melting during spring and early summer could change considerably (Eicken et al., 2004). Therefore, we performed most of our thickness measurements by means of nondestructive electromagnetic inductive (EM) sounding (Kovacs and Morey, 1991; Haas et al., 1997), which can be performed by simply moving an EM instrument above the snow surface, and which is therefore a preferred method for temporal studies of ice thickness change (Eicken et al., 2001).

The accuracy of EM sea-ice thickness surveys depends on a knowledge of the electrical conductivity of the ice. In most cases, the effects of varying ice conductivity can be neglected (Haas et al., 1997; Reid et al., 2006b), or can be corrected for by comparison with drill-hole measurements. However, during ISPOL, we wanted to avoid drilling holes for the reasons explained above, but were also possibly expecting large changes of sea-ice conductivity as a result of ice warming and associated increases in porosity and permeability. Therefore, we also conducted EM and direct- current geoelectrical (DC) depth sounding (Reid et al., 2006b) of ice conductivity to identify and quantify those changes. Here, we present the results of those conductivity measurements, and discuss the concurrent effects of ice thickness and conductivity changes, which both affect the measured EM signal and can therefore not easily be separated from each other.

\section{Measurements and methods}

Most measurements reported here were performed on the ISPOL ice floe during the drift period between November 27, 2004, and January 2, 2005, when the floe drifted a net distance of $98 \mathrm{~km}$ from a position of $68^{\circ} 10^{\prime} \mathrm{S}$, $54^{\circ} 48^{\prime} \mathrm{W}$ (Fig. 1), to $67^{\circ} 22^{\prime} \mathrm{S}, 55^{\circ} 24^{\prime} \mathrm{W}$ (Hellmer et al., 2006, 2008; Dieckmann et al., 2007). Satellite radar imagery revealed that the floe was located at the boundary between two south-north extending bands of sea-ice with high and low backscatter towards the east and west, respectively (Fig. 1; Hellmer et al., 2006). Based on backward tracking of radar imagery from November to January 2004, the bright band was interpreted as a region of predominantly second-year ice, and the dark band as first-year ice (FYI) formed since March 2004 in a prominent recurring polynya off the Ronne Ice Shelf $800 \mathrm{~km}$ south of the study region. Initially, the floe was approximately $10 \mathrm{~km}$ in diameter, but suffered from two major break-up events, decreasing its size to approximately $1200 \times 1200$ and $700 \times 700 \mathrm{~m}^{2}$, respectively (Fig. 2; McPhee, 2008). On the floe different sampling sites were established on different-level ice types and numbered according to Table 1 . The location of sites $9 \mathrm{a}$ and $9 \mathrm{~b}$ are indicated in Fig. 2. The location of all other sites is shown on the maps of Hellmer et al. (2008).

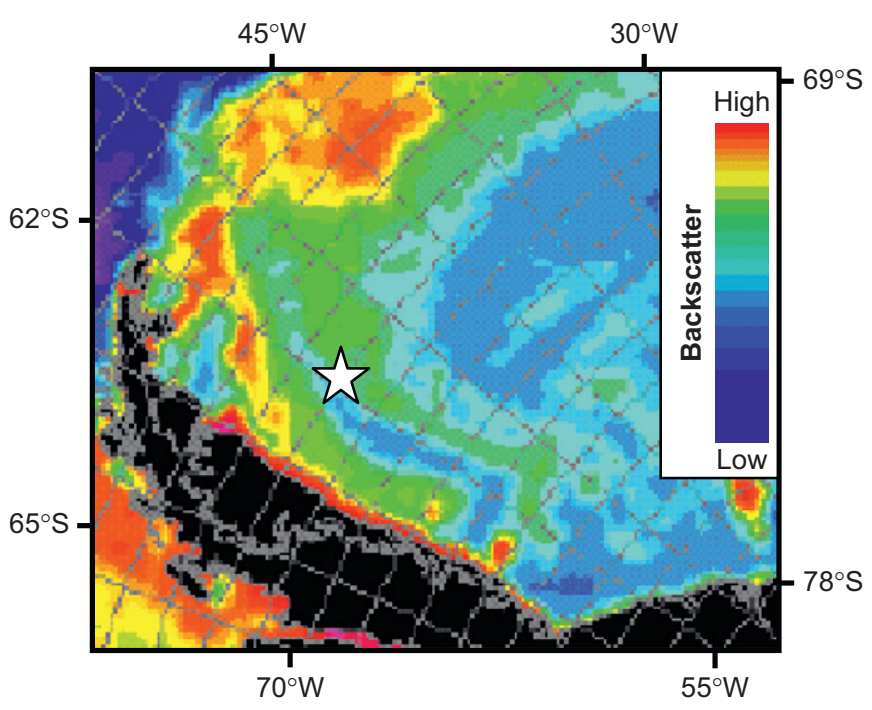

Fig. 1. Map of QuickScat radar backscatter coefficients in the Weddell Sea acquired on November 10, 2004, showing the initial location of the ISPOL floe (star) relative to different first-year and second-year ice regimes; Yellow/red: high backscatter; blue/purple: low backscatter. Image courtesy Leif Toudal/DTU. 


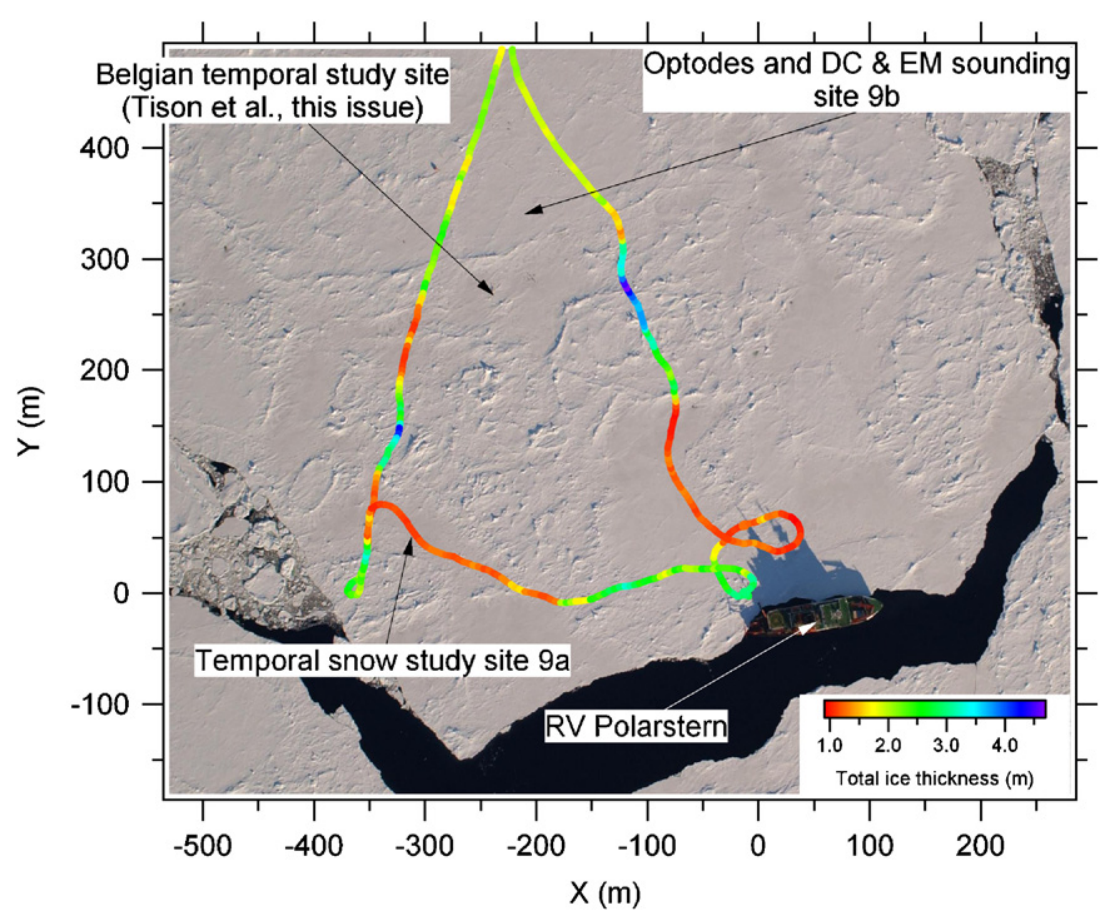

Fig. 2. Nadir-looking aerial photograph of the ISPOL floe on December 26, after the final floe break-up (cf. Hellmer et al., 2008). Colour-coded line shows ice thickness profile along skidoo track. Note composition of ice floe of thick rough SYI floe fragments and greyish, smooth thin FYI in between. Locations of sampling sites $9 \mathrm{a}$ and $9 \mathrm{~b}$ are indicated (cf. Table 1).

Table 1

Summary of main sampling sites on the ISPOL floe (cf. Fig. 4 and Hellmer et al., 2008)

\begin{tabular}{|c|c|c|c|c|c|c|}
\hline Site & Ice type $^{\mathrm{a}}$ & Main activities & $\mathrm{FB}_{\text {pred }}$ & $Z_{\mathrm{tt}}(\mathrm{m})$ & $Z_{\mathrm{s}}(\mathrm{m})$ & $S(\mathrm{ppt})$ \\
\hline 5 & SYI & Three ice coring campaigns & neg & $2.85 \pm 0.37$ & 0.95 & 4.08 \\
\hline 6 & FYI & Main German temporal ice and snow study & neg & $1.27 \pm 0.04$ & 0.32 & 5.06 \\
\hline 7 & SYI & Ocean and atmosphere turbulence masts & neg & $3.51 \pm 0.79$ & $0.75^{\mathrm{c}}$ & n.d. \\
\hline 8 & SYI & Temporal snow study & neg & $3.29 \pm 0.82$ & 0.81 & 4.39 \\
\hline $9 \mathrm{a}$ & FYI & Temporal snow study & pos & $1.30 \pm 0.10$ & 0.14 & n.d. \\
\hline $9 b$ & Thick FYI & $\begin{array}{l}\text { Sediment trap, biogeochemistry, } \mathrm{CO}_{2} \\
\text { measurements, DC geoelectric and EM sounding }\end{array}$ & pos & $2.00 \pm 0.14$ & $0.30^{\mathrm{c}}$ & 4.55 \\
\hline FIMR $^{\mathrm{b}}$ & FYI & Northernmost buoy deployment & neg & n.d. & 0.28 & n.d. \\
\hline Buoy "W"b & Thick FYI & Southernmost buoy deployment & pos & 2.11 & 0.30 & 4.45 \\
\hline
\end{tabular}

$\mathrm{FB}_{\text {pred }}$ is the predominant freeboard (positive or negative), $Z_{\mathrm{tt}}$ and $Z_{\mathrm{s}}$ are initial mean total ice and snow thickness, and $S$ is initial mean ice core salinity.

${ }^{a}$ FYI and SYI are first- and second-year ice, respectively.

${ }^{b}$ FIMR and Buoy "W" buoy deployment sites were located approximately 100 and $60 \mathrm{~km}$ north and south of the ISPOL floe, respectively (Heil et al., 2008).

${ }^{\mathrm{c}}$ Snow thickness spot measurements have only been performed at a few locations.n.d.: not determined.

Measurements of total ice thickness (ice plus snow thickness) were mainly performed by means of groundbased and airborne EM thickness profiling. Ground-based EM thickness surveys were carried out by means a Geonics EM31 instrument pulled with a skidoo along the main service routes established to the different sampling sites (Figs. 2 and 4; Kovacs and Morey, 1991; Haas et al., 1997; Eicken et al., 2001; Hellmer et al., 2008). The EM data were geocoded by means of coincident satellite Global Positioning System (GPS) measurements, and were subsequently corrected for ice drift and varying driving speed to derive an equidistant profile of ice thickness along the skidoo tracks. Unfortunately, due to the two floe break-up events, only a $600-\mathrm{m}$-long coincident profile could be measured on all surveys. One EM grid-survey over the entire floe was performed at the beginning of the drift using a purposebuilt helicopter-borne EM (HEM) instrument (Haas et al., 2006).

The accuracy of helicopter-borne and ground-based EM thickness measurements is better than $\pm 0.1 \mathrm{~m}$ over level ice (Haas et al., 1997; Pfaffling et al., 2007). However, over ridges and deformed ice, due to the footprint of the measurements of up to 3.7 times the flying altitude, and due to the porosity of ridge keels, the maximum thickness of pressure ridges and deformed ice can be underestimated by as much as 50\% (Haas et al., 1997; Haas and Jochmann, 
2003; Reid et al., 2006a). During ISPOL, the accuracy of the calibration of the ground-based EM estimates was confirmed only by a few drill-hole measurements on level ice, away from the main study sites to avoid disturbance of the hydraulic system of the ice (see above). Overall, drillhole measurements and ground-based and helicopter-borne thickness estimates agreed well within the stated accuracy of $\pm 0.1 \mathrm{~m}$ over level ice.

Repeated ruler-stick snow thickness surveys were performed along 50-m-long profiles with a point spacing of $1 \mathrm{~m}$ on level-ice of the different sampling sites to observe their mean snow thickness and temporal change (Table 1; Nicolaus et al., 2006). On December 17, a 1070-m-long snow thickness profile was surveyed with a point spacing of $10 \mathrm{~m}$ along the main ground-based EM profile to characterize the overall snow thickness distribution of the ISPOL floe, including regions that were not chosen for dedicated temporal studies. The accuracy of ruler stick measurements is generally better than $\pm 0.02 \mathrm{~m}$, taking into account the centimetre to decimetre, small-scale variability of snow thickness. However, under summer conditions measurements can be corrupted by the presence of ice layers and hard, high-density wind-packed snow, leading to underestimated snow thicknesses.

On several days, and at least at the beginning and end of the observation period, ice cores were drilled at the different sampling sites to further characterize ice types and to observe temporal changes of vertical ice temperature and salinity profiles. Temperature measurements were performed on the ice directly after core retrieval, and salinity was measured on melted samples, which were first stored at $-25^{\circ} \mathrm{C}$ and analysed on the ship for ice texture by means of visual inspections of ice thick-sections in polarized light (Lange, 1988). Subsequently, brine volume (porosity) $\Phi$ was calculated from ice temperature and salinity. The equations of Cox and Weeks (1983) were used for ice colder than $-2{ }^{\circ} \mathrm{C}$, and equations of Leppäranta and Manninen (1988) for ice between -2 and $0^{\circ} \mathrm{C}$. Based on those porosity estimates and ice temperature measurements, electrical brine conductivity $\sigma_{\mathrm{b}}$ was derived (Stogryn and Desargant, 1985) and electrical direct-current (DC) ice conductivity $\sigma_{\mathrm{i}}$ was calculated according to Archie's Law

$\sigma_{\mathrm{i}}=\sigma_{\mathrm{b}} \Phi^{m}$

with the cementation factor $m$ (Archie, 1942; Haas et al., 1997; Reid et al., 2006b). As in those earlier studies, here we use $m=1.75$.

Two different classical geophysical electrical conductivity depth-sounding measurements were performed on thick, level FYI at site 9b. Three DC geoelectric measurements of ice thickness and resistivity were performed on December 4, 18, and 30. With DC geoelectrical depth sounding (Telford et al., 1990), an electrical current within the ice is injected by means of two current electrodes placed on the ice surface, and the voltage in-between is measured by two potential electrodes to obtain a measure of electrical resistivity (Telford et al., 1990). With successively increas- ing electrode spacing around a fixed midpoint, the current flow includes deeper and deeper ice layers. Thus, a vertical profile of ice conductivity can be obtained. Here, DC depth sounding was performed with the so-called Wenner configuration, i.e. with equal spacing between each current and potential electrode for each individual resistivity measurement (Telford et al., 1990; Reid et al., 2006b). Current flow and resistivity measurements were controlled with a GeoTom2000 instrument. From those measurements, ice thickness and conductivity were calculated by means of two- and three-layer least-squares inversion using the Marquardt-Levenberg modification (Lines and Treitel, 1984) to the Gauss-Newton equation as inversed method. In this method, both the sum of squares of the differences between the model and the observed data values and a combination of the magnitude of these differences and the model parameter change are minimized. This method can be successfully used especially in the inversion of DC sounding data where the model consists only of a small number of layers. Here, the inversion was performed with the software package RES1D (Loke, 2001).

Due to the vertical alignment of brine channels forming the main conduits for electrical currents, sea-ice conductivity is characterized by a strong anisotropy. As demonstrated by several earlier studies summarized by Reid et al. (2006b), anisotropy results in a 9-12 times higher vertical $\left(\sigma_{\mathrm{v}}\right)$ than horizontal $\left(\sigma_{\mathrm{h}}\right)$ ice conductivity. Here, anisotropy was calculated by the coefficient of anisotropy $f$, defined as

$f=\frac{t_{\mathrm{DC}}}{t}=\sqrt{\frac{\sigma_{\mathrm{h}}}{\sigma_{\mathrm{v}}}}$

with true ice thickness $t$ and ice thickness $t_{\mathrm{DC}}$ inferred from inversion of DC geoelectrical depth sounding (Reid et al., 2006b).

Due to the physics of EM induction in conductive media, EM measurements over level sea-ice are only sensitive to the horizontal ice conductivity (McNeill, 1980; Reid et al., 2006b). In general, for any given constant true ice thickness, increases of ice conductivity will result in increases of the electromagnetically measured apparent conductivity. This will be interpreted as thinner ice if the ice conductivity change was not taken into account, as is generally true for the calculation of ice thickness from EM31 data (Haas et al., 1997).

On December 19, 2004, and January 1, 2005, at the same site two EM depth sounding measurements of ice thickness and conductivity were performed in addition. For these, the EM instrument was operated in horizontal (HDM) and vertical dipole mode (VDM). Measurements were performed at increasing instrument heights between 0.5 and $1.8 \mathrm{~m}$ above the ice surface. Thus the depth of maximum EM induction ("centroid depth") within the ice was raised, making the measurement sensitive to vertical conductivity changes (McNeill, 1980). In addition, EM soundings at different instrument heights provide independent measurements for the comparison with 1D model curves of the EM 
response over ice with varying thickness and conductivity (Anderson, 1979; see Results section).

\section{Results}

\subsection{Ice types and ice thickness on ISPOL floe}

Fig. 3 shows the distribution of total ice thickness of the original ISPOL floe obtained by HEM profiling on November 27, the first day of observations on the ISPOL floe. Sixteen lines with a spacing of approximately $100 \mathrm{~m}$ were flown across the $100 \mathrm{~km}^{2}$ floe, with a total track length of approximately $140 \mathrm{~km}$. The thickness distribution is characterized by a strong mode between 2.4 and $2.9 \mathrm{~m}$, representing thick FYI and second-year ice (SYI; see below). This was the predominant ice type, with $22 \%$ of all data in this thickness range. $68 \%$ of all measurements were thicker than $2.4 \mathrm{~m}$. There is another clear but smaller mode at $1.15 \mathrm{~m}$, comprising only $1 \%$ of all data. The mode at

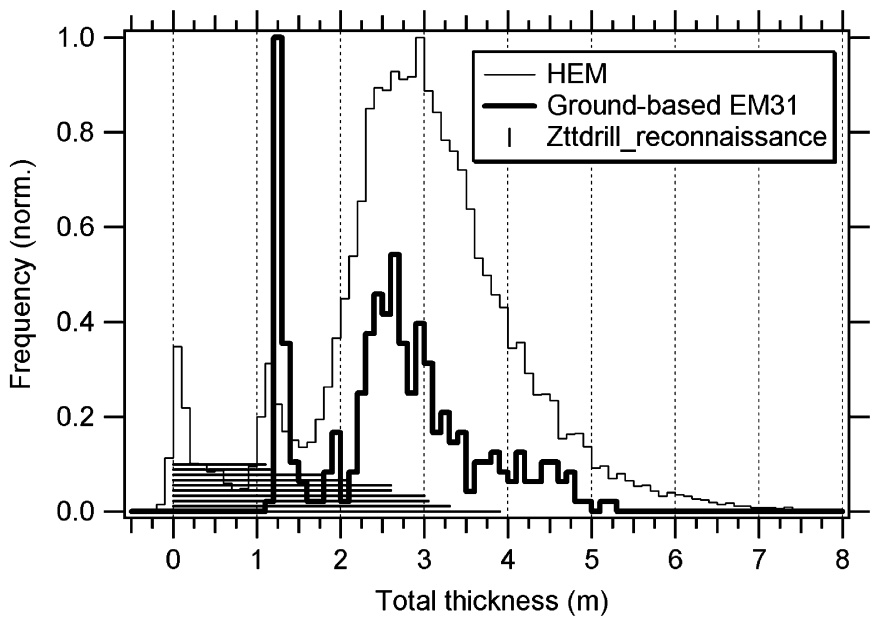

Fig. 3. Ice thickness distribution of the original ISPOL floe, obtained by HEM surveying on November 27 and by ground-based EM sounding along the skidoo track across sampling sites 5, 6, 7, 8, and 9. Horizontal bars show the results of 10 drill-hole measurements performed by the international floe reconnaissance team.
$0.05 \mathrm{~m}$ shows the presence of open water around the floe in the beginning of the observation period. The mean ice thickness was $3.01 \pm 1.09 \mathrm{~m}$, excluding ice thicknesses $<0.2 \mathrm{~m}$ representative of open water and new ice.

Fig. 3 also includes the result of a ground-based thickness survey performed between November 28 and December 1 across sampling sites 5, 6, 7, 8, and 9 (see Fig. 4 and Hellmer et al., 2008). It is characterized by a strong mode of $1.25 \mathrm{~m}$ representing thin FYI, and another mode between 2.4 and $2.7 \mathrm{~m}$, in good agreement with the HEM results. The mean thickness of that profile was $2.64 \mathrm{~m}$. For comparison, Fig. 3 also shows the results of 10 drill-hole measurements performed during the initial floe reconnaissance at random locations on November 26. Interestingly, even those few measurements provide a good sub-sample of the main ice thickness classes.

The ground-based thickness profile across all major sampling sites is shown in Fig. 4. Results are summarized in Table 1. It can be nicely seen that the floe consisted of areas with thick, deformed ice, and level thin ice, and that the mean level ice thicknesses are in close agreement with the thin-ice modes of Fig. 3. As will be shown later with the ice-core analyses, most thick ice was SYI, while the thin ice was FYI. The sediment trap and biogeochemistry site (site 9 b; Papadimitriou et al., 2007) was rather level with a low standard deviation, too, but the total thickness was quite high, indicating thick FYI (Table 1). This will be discussed with the presentation of the ice-core analyses.

Unfortunately, no systematic snow thickness measurements were made along the EM thickness profile in Fig. 4. Therefore, Fig. 5 presents the snow thickness distribution of a 1070-m-long profile across sites 8 and 9 . The histogram shows two modes, one between 0.2 and $0.5 \mathrm{~m}$, and one at $0.75 \mathrm{~m}$, with an overall mean of $0.60 \pm 0.31 \mathrm{~m}$. The modes are in general agreement with the mean snow thickness at the snow monitoring sites representative of FYI and SYI (see Fig. 8 below).

Results from ice-core analyses of thick ice are shown in Fig. 6. The thin FYI cores at sites 6 were characterized mostly by granular ice of snow ice origin at the top and

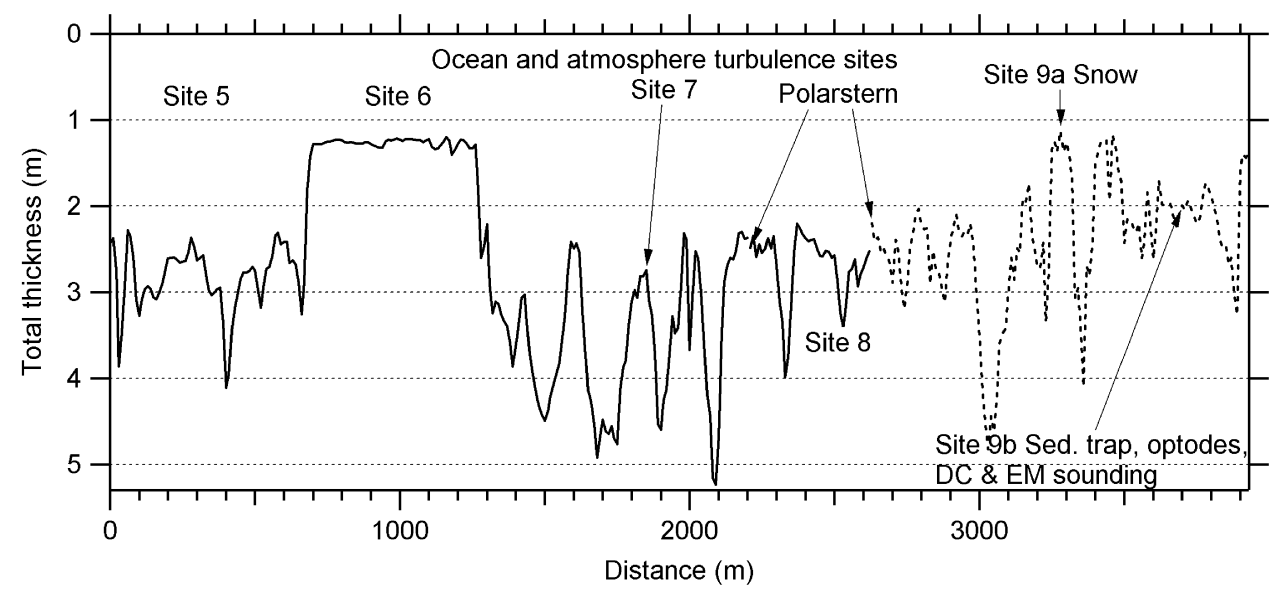

Fig. 4. Ice thickness profile across the main sampling sites obtained between November 28 (solid line) and December 1 (stippled line). 
columnar ice underneath, and typical C-shaped salinity profiles (Hellmer et al., 2006). The same was found by Tison et al. (2008) for site 9a. However, most of the thicker ice, which also was covered by thick snow, had a more

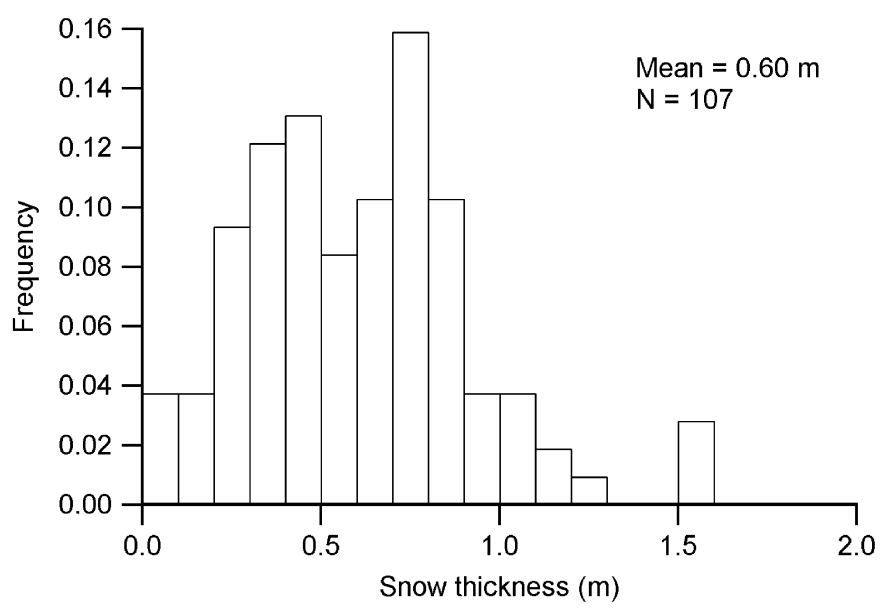

Fig. 5. Snow thickness distribution along the skidoo track between R.V. Polarstern (site 8) and the floe edge on site 9, obtained on December 17. variable ice stratigraphy, with alternating layers of columnar and granular ice as a result of variable growth conditions during the lifetime of the floe. Most strikingly, the 1.81-m-thick ice at site $9 \mathrm{~b}$ was composed almost exclusively of columnar ice. Its snow and ice thickness and stratigraphy were very similar to an ice core sampled at the southernmost buoy deployment site "W", at $68^{\circ} 50^{\prime} \mathrm{S}$, $56^{\circ} 03^{\prime} \mathrm{W}$ (Heil et al., 2008). As the latter was located well within the low backscatter band of the scatterometer data (Fig. 1), we assume that the ice at site $9 \mathrm{~b}$ was indeed FYI from the Ronne polynya as well.

Initial mean ice-core salinities amounted to 5.06, 4.08, 4.39 , and $4.55 \mathrm{ppt}$, at sites $6,5,8$, and $9 \mathrm{~b}$, respectively (Table 1). The mean salinity at the buoy deployment site $\mathrm{W}$ was $4.45 \mathrm{ppt}$. Note that these values are all very similar, and do not show clear differences between different ice types.

During ice-core drilling, the best observations of freeboard were obtained. Results of numerous measurements are listed in Table 1. Site 6 was characterized by negative freeboard of a few centimetres, while the freeboard of the thin FYI at site $9 \mathrm{a}$ was positive, similarly to observations of Tison et al. (2008). The thick FYI of site $9 \mathrm{~b}$ and at buoy

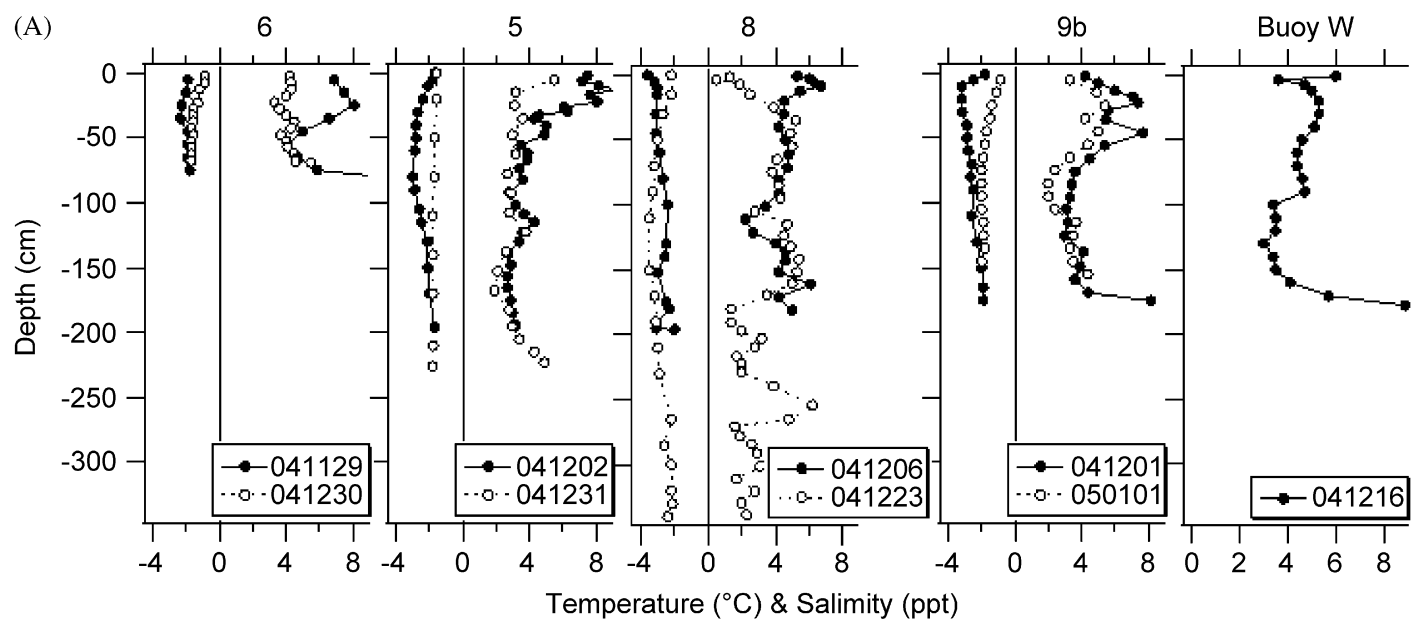

(B)

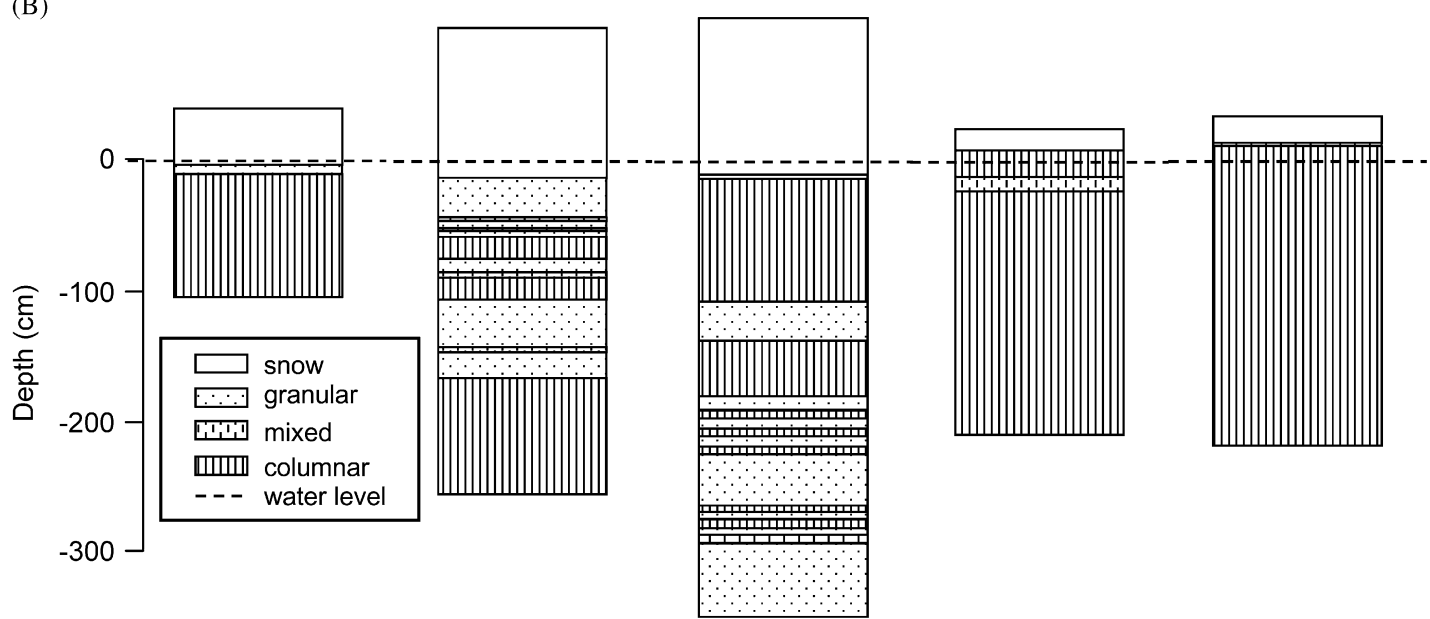

Fig. 6. Depth profiles of temperature and salinity of sites 6, 5 and 8, and $9 \mathrm{~b}$ and buoy deployment site "W", respectively, obtained in the beginning and end of the observation period, and typical profiles of ice texture. Figure legends show dates of sampling (yymmdd). Horizontal stippled line in (b) shows location of water level. 
"W" had a positive freeboard mostly exceeding $0.05 \mathrm{~m}$ due to the relatively thin snow cover. In contrast, the SYI at sites 5 and 8 had mostly strongly negative freeboard below $-0.15 \mathrm{~m}$, as a result of the very thick snow cover (Table 1). Upon drilling some holes there, water came up through the holes for more than a week, flooding large areas around the drill-holes, making subsequent measurements and sampling most problematic.

\subsection{Ice and snow thickness change}

In Fig. 7, the thickness distributions obtained from repeated surveys of the main skidoo track are presented to show the temporal evolution of ice thickness between December 4 and 30. The bin width of the histograms is only $0.2 \mathrm{~m}$ to reduce noise due to the small number of only 60 measurements along each profile. As in Fig. 3, two modes representing SYI and thin FYI can be seen. The thin FYI mode of $1.3 \mathrm{~m}$ did not change during the 18-day period, indicating that the overall FYI thinning did not exceed 0.2. However, there is a marked $0.4 \mathrm{~m}$ decrease of the SYI mode, from $2.5 \mathrm{~m}$ on December 4 to $2.1 \mathrm{~m}$ on December 30 . As will be shown below, it is not clear whether this was due to bottom melt, or due to changes of the ice conductivity resulting from the observed ice warming.

Some or all of the observed decrease of total ice thickness is also attributable to the thinning of snow as shown in Fig. 8 (see also Nicolaus et al., 2006). The figure presents the mean snow thicknesses of all measurements

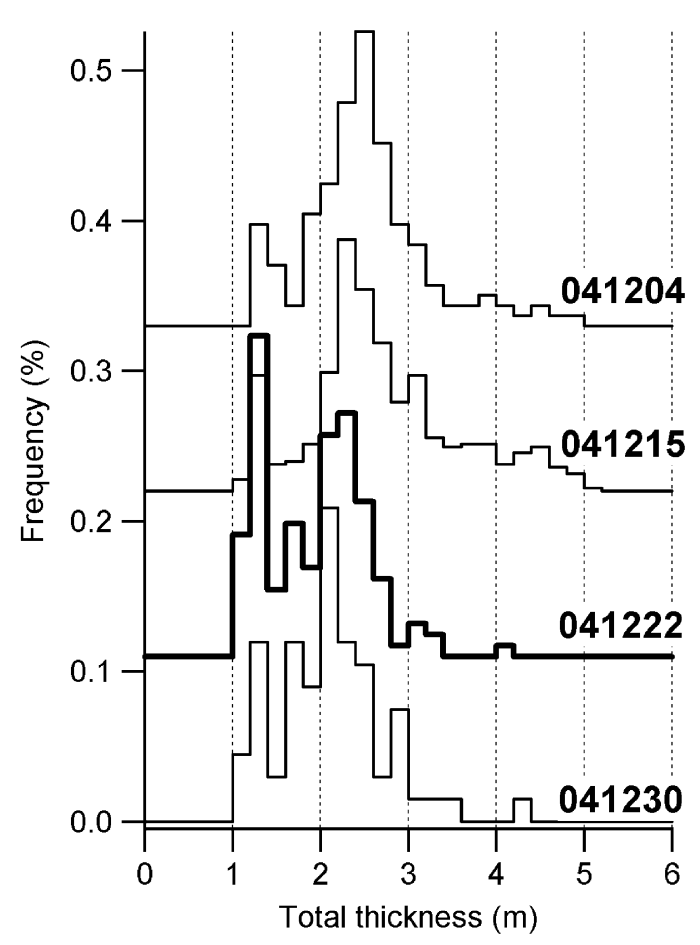

Fig. 7. Ice thickness distributions obtained from repeated ground-based EM profiling along the original skidoo track on site 9 (left, almost straight profile in Fig. 2).

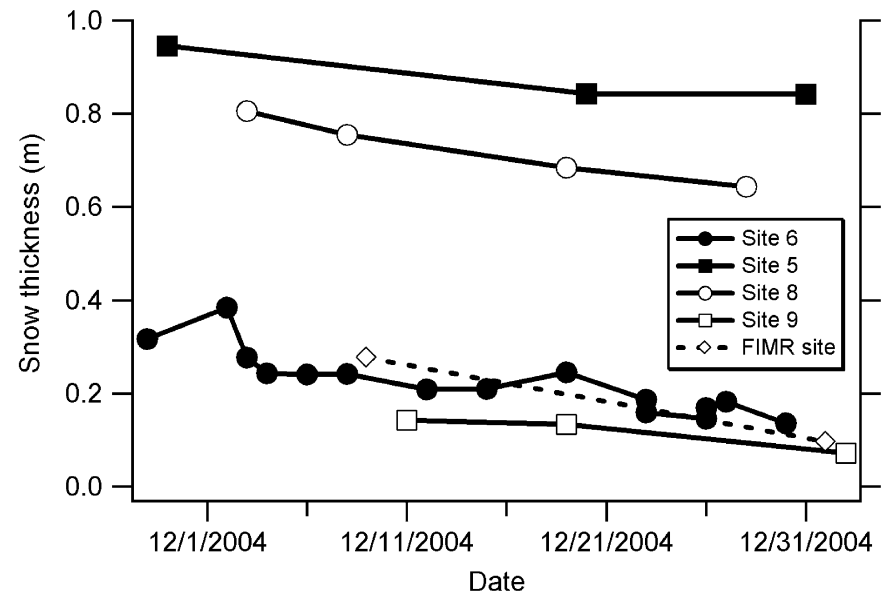

Fig. 8. Mean snow thickness of the main sampling sites and their temporal change during the ISPOL study period measured along $50 \mathrm{~m}$ long profiles with a point spacing of $1 \mathrm{~m}$. FIMR site was located on an ice floe about $60 \mathrm{~km}$ north of the ISPOL floe.

performed along $50 \mathrm{~m}$ profiles at irregular temporal sampling intervals. Snow thickness measurements on site 6 were slightly biased by repeated crack formation across the profile, and the subsequent movement of the profile to another location on the same site. In the beginning of the observation period, mean snow thicknesses amounted to $0.32,0.14$, and $0.28 \mathrm{~m}$ on the FYI sites 6,9 , and the Finish Institute of Marine Research (FIMR), a buoy deployment site located about $100 \mathrm{~km}$ north of the ISPOL floe (Heil et al., 2008), and to 0.95 and $0.81 \mathrm{~m}$ on the SYI sites 5 and 8 . These decreased by $0.18,0.07$, and $0.18 \mathrm{~m}$ on sites 6,9 , and FIMR, and by 0.11 and $0.17 \mathrm{~m}$ at sites 6 and 8 , respectively, i.e. by less than $0.20 \mathrm{~m}$. Linear regression of the decrease results in thinning rates of $0.51,0.33$, and $0.78 \mathrm{~cm} / \mathrm{d}$ on sites 6,9 , and FIMR, and 0.49 and $0.64 \mathrm{~cm} / \mathrm{d}$ in sites 5 and 8 , respectively.

\subsection{Warming of snow and ice and related changes of electrical properties}

The profiles in Fig. 6 show that the temperature at the snow/ice interface and in the upper ice layers increased during the observation period at all sites. The warming ranged between 0.1 and $1.4^{\circ} \mathrm{C}$ at the snow/ice-interface, and between 0.75 and $1.9^{\circ} \mathrm{C}$ in the upper ice layers. These values are in agreement with snow temperature measurements of Willmes et al. (2006), who show that the upper few decimetres of the snow were actually at the melting temperature of $0{ }^{\circ} \mathrm{C}$, and that there was a steady warming of the lower snow layers. Simultaneously with the ice warming and associated increase of porosity, mean ice salinities decreased by $1.07,2.28,0.85$, and $0.93 \mathrm{ppt}$ at sites $5,6,8$, and 9 , respectively (see Table 1 for initial values). Comparable results are presented by Hellmer et al. (2006), and Tison et al. (2008) for the thin FYI of their site.

The warming and associated changes of ice salinity, brine volume, and conductivity in the 1-month period 


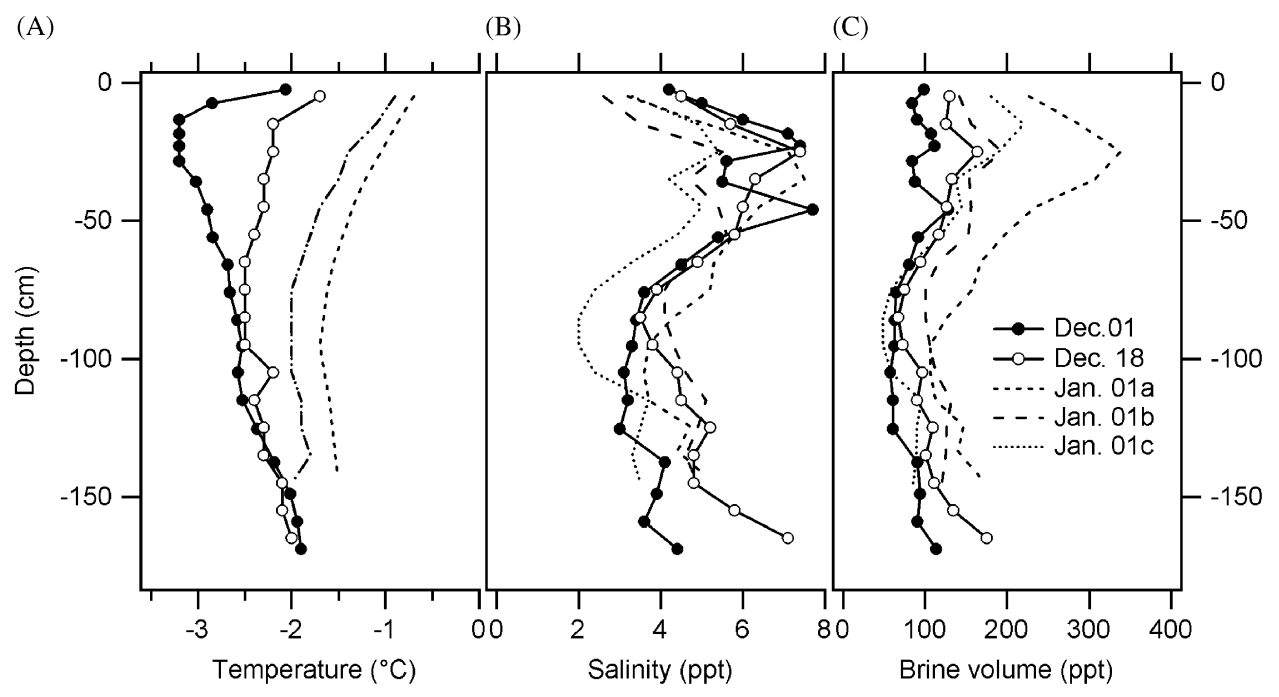

Fig. 9. Temporal evolution of (A) temperature, (B) salinity, and (C) brine volume profiles at the DC geoelectrics and EM sounding site 9b. On January 1, temperature was only measured on two cores.

between December 1, 2004 and January 1, 2005, are shown in more detail in Fig. 9 for the thick FYI at site 9b, where DC depth sounding has been performed (cf. Fig. 6). Note that three ice cores were analysed on January 1, showing the range of natural lateral variability and the amount of sampling bias. The mean ice temperature increased from -2.6 to $-1.7^{\circ} \mathrm{C}$ (Fig. 9A). Mean salinity was $4.5 \mathrm{ppt}$ on December 1 and ranged between 5.0 and $3.6 \mathrm{ppt}$ on January 1 (Fig. 9B). As a consequence, mean brine volume increased from $84 \mathrm{ppt}$ to between 110 and $189 \mathrm{ppt}$ (Fig. 9C). The increasing brine volume and temperature also resulted in higher ice conductivities, which increased from $47 \mathrm{mS} / \mathrm{m}$ to between 52 and $110 \mathrm{mS} / \mathrm{m}$.

\subsection{Changes of electrical properties inferred from $D C$ geoelectrical sounding}

Fig. 10 shows the results of the DC geoelectric depth sounding, which was performed on December 4, 18, and 30 , i.e. within a few days of the ice-core analyses presented in Fig. 9. The curves clearly show the presence of a highly resistive sea-ice layer over conductive sea water, as can be seen from high (low) apparent resistivities for short (long) electrode spacings. The lines in Fig. 10 show model curves calculated for ice thicknesses and ice and water conductivities resulting from the inversion of the sounding curves (Loke, 2001). The model curves are in very good agreement with the DC measurements. According to the inversion results, ice conductivity increases from 37 to $97 \mathrm{mS} / \mathrm{m}$ (Table 2). However, derived water conductivities are lower by up to $60 \%$ than the true water conductivity of approximately $2700 \mathrm{mS} / \mathrm{m}$. This could be a result of poor coupling conditions between electrodes and ice, which have a stronger effect on the derived water properties than on the inverted ice properties. Also inverted ice thicknesses of

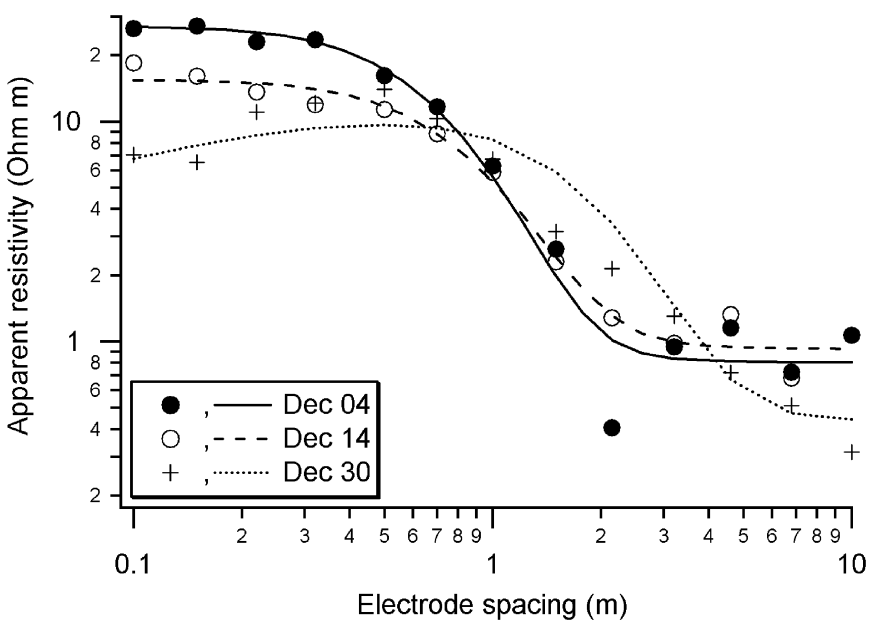

Fig. 10. Results of DC geoelectrical depth sounding using the Wenner electrode array at site $9 \mathrm{~b}$. Symbols show the observed apparent resistivity measured on three different days, and lines show model curves calculated from the results of a two- (December 04 and 14) and three-layer (Dec. 30) least-square inversion of the sounding data in Table 2.

Table 2

Ice and water conductivity and thickness resulting from two- and threelayer least-squares inversion of DC geoelectric sounding measurements

\begin{tabular}{llcl}
\hline Measurement & Layer no. & Conductivity $(\mathrm{mS} / \mathrm{m})$ & Thickness $(\mathrm{m})$ \\
\hline Dec. 04 & 1 & 37 & 0.45 \\
& 2 & 1248 & $\infty$ \\
Dec. 18 & 1 & 65 & 0.55 \\
& 2 & 1086 & $\infty$ \\
Dec. 30 & 1 & 189 & 0.07 \\
& 2 & 92 & 1.04 \\
& 3 & 2315 & $\infty$ \\
\hline
\end{tabular}

Model curves calculated with the thicknesses and conductivities shown here are presented in Fig. 10. 
$0.45-1.10 \mathrm{~m}$ (Table 2) disagree strongly with the true ice thickness of $1.77-1.54 \mathrm{~m}$ measured by drilling (Table 3).

This latter disagreement can be largely attributed to the anisotropy of sea-ice conductivity. Resulting values for the coefficient of anisotropy $f$ and horizontal and vertical conductivities $\sigma_{\mathrm{h}}$ and $\sigma_{\mathrm{v}}$ according to Eq. (2) are given in Table 3. $f$ ranges between 0.25 and 0.72 , in agreement with the results of Reid et al. (2006b). Over the study period, $\sigma_{\mathrm{h}}$ increased from 9 to $70 \mathrm{mS} / \mathrm{m}$, and $\sigma_{\mathrm{v}}$ ranged between 136 and $192 \mathrm{mS} / \mathrm{m}$. Both variables are within the range of the calculated increase of ice-core conductivities presented above. The increasing horizontal conductivity might indicate a higher permeability and horizontal connectivity of pores due to the warming.

Fig. 11 shows the results of the two EM depth sounding measurements performed to investigate the effect of the increased horizontal ice conductivity on the resulting ice thickness retrieval. In fact, an increase of apparent conductivity of $10-20 \mathrm{mS} / \mathrm{m}$ can be seen between all EM sounding measurements on December 19 and on January 1, respectively, although the drill-hole measured ice thickness remained almost constant (Table 3). For

Table 3

Results of anisotropy analysis of results of DC geoelectric sounding (Eq. (2))

\begin{tabular}{lllllll}
\hline Date & $t(\mathrm{~m})$ & $t_{\mathrm{DC}}(\mathrm{m})$ & $I_{\mathrm{m}}(\mathrm{mS} / \mathrm{m})$ & $f$ & $I_{\mathrm{h}}(\mathrm{mS} / \mathrm{m})$ & $I_{\mathrm{v}}(\mathrm{mS} / \mathrm{m})$ \\
\hline Dec. 04 & 1.77 & 0.45 & 37 & 0.25 & 9 & 145 \\
Dec. 18 & 1.61 & 0.55 & 65 & 0.34 & 22 & 192 \\
Dec. 30 & 1.54 & 1.10 & 97 & 0.72 & 70 & 136 \\
\hline
\end{tabular}

$t$ is the drill-hole measured ice thickness. $t_{\mathrm{DC}}$ and $I_{\mathrm{m}}$ are the ice thickness and ice conductivity derived from DC measurements (Table 2). $I_{\mathrm{v}}$ and $I_{\mathrm{h}}$ are the vertical and horizontal ice conductivity, and $f$ is the anisotropy factor.

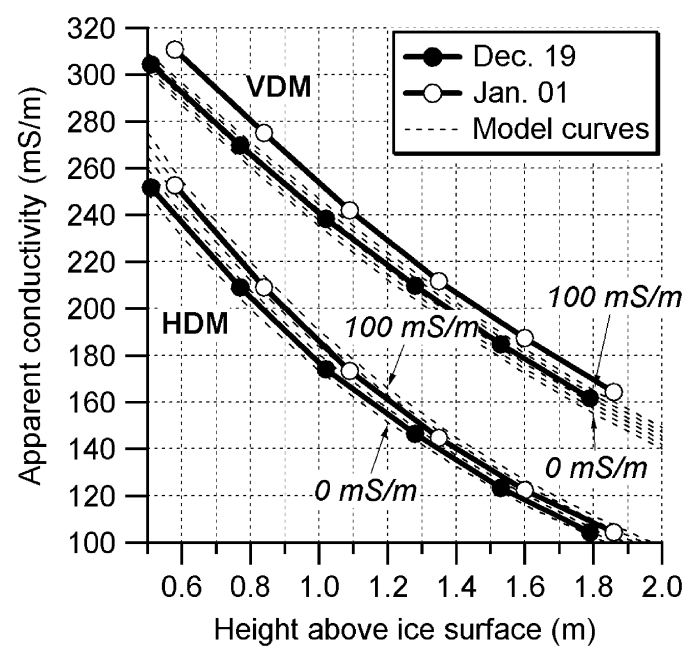

Fig. 11. Results of EM depth sounding on December 19 and January 1, performed with an EM instrument in vertical (VDM) and horizontal dipole mode (HDM; symbols and thick lines). Dashed lines show 1D model curves calculated for a 1.5 -m-thick layer of ice with variable conductivity from 0 to $100 \mathrm{mS} / \mathrm{m}$ (increments $20 \mathrm{mS} / \mathrm{m}$ ) over a water layer with a conductivity of $2700 \mathrm{mS} / \mathrm{m}$. comparison, Fig. 11 also includes model curves that show the calculated EM response for the given constant ice thickness of $1.5 \mathrm{~m}$ for variable ice conductivities between 0 and $100 \mathrm{mS} / \mathrm{m}$. The measured data and their temporal change fall well within the range of the model curves. Only the VDM measurement on January 1 is slightly higher than the model curve for an ice conductivity of $100 \mathrm{mS} / \mathrm{m}$ which might be a measurement bias.

The main conclusion of the calculated and measured EM responses in Fig. 11 is that changes of ice conductivity from 0 to $100 \mathrm{mS} / \mathrm{m}$ of 1.5 -m-thick ice only result in small changes in the electromagnetically measured apparent conductivity of less than $20 \mathrm{mS} / \mathrm{m}$. If the ice conductivity increase was not taken into account, inversion of the increased-measured apparent conductivity would result in smaller calculated ice thicknesses. However, Fig. 11 shows that the underestimation of ice thickness scarcely exceeds $0.1 \mathrm{~m}$. Therefore, results of repeated thickness transects shown in Fig. 7 are hardly biased by changes of ice conductivity.

\section{Discussion}

Results presented in this paper give the best available synthesis of initial ice types and properties of the ISPOL floe. While most ISPOL studies have focussed only on measurements on the thin FYI for practical reasons, this paper also presents most measurements performed over the thick, predominantly SYI. As demonstrated with the thickness measurements, the ISPOL floe was mostly composed of thick SYI with a total thickness of $2.4-2.9 \mathrm{~m}$, and $68 \%$ of all measurements were thicker than $2.4 \mathrm{~m}$. Snow thickness measurements showed that the mode included $0.7-1.0 \mathrm{~m}$ of snow. The presence of thin FYI with total thicknesses of $1.10-1.30 \mathrm{~m}$, including $0.2-0.4 \mathrm{~m}$ of snow was also clearly revealed by the thickness measurements. However, the presence of older, thick FYI with total thicknesses between 1.8 and $2.1 \mathrm{~m}$, mostly covered by $0.3 \mathrm{~m}$ of snow, was only revealed by the additional analysis of ice cores and the comparison with an ice core taken at buoy "W", in a region with more uniform ice conditions. This ice type was not easily separable from the SYI based on ice thickness measurements alone (Fig. 3). Here, results of ice core analyses and backscatter maps derived from satellite scatterometry proved invaluable in addressing the nature and origin of different ice regimes. Therefore, the interpretation of the different ice types is that the ISPOL floe was mainly composed of SYI and thick FYI, reflecting its location at the boundary between two prominent backscatter regions (Fig. 1). The thin FYI was only present at a few locations between the older floe fragments (Fig. 2), and did develop after a few major ice deformation events. It would be a challenge for studies of satellite ice deformation and atmospheric pressure patterns to find events that could have resulted in the formation of these prominent thin FYI patches and refrozen cracks during the preceding winter. 
This study demonstrated the power of ice thickness measurements for addressing different ice types, and the potential of EM sounding for obtaining representative ice thickness distributions. Although Lange and Eicken (1991) have shown the general coexistence of SYI and FYI in the northwestern Weddell Sea by means of ice thickness drilling, their results only show the general characteristics of a large region. It would have been hard to obtain the same amount of thickness data of the ISPOL floe by drilling. However, the inability of EM measurements to distinguish between ice and snow thickness is a big problem, and thus we rely on spot measurements and the one long snow-thickness profile for a general overview of the snow thickness distribution on the ISPOL floe.

EM measurements of seasonal ice thickness change also are hampered by coincident changes of ice conductivity. Although our DC geoelectric and EM sounding measurements showed that these effects are not very large, they might still prevent observations of very small thickness changes, as was the case in the present study. More seriously, EM thickness measurements are also affected by flooding, as the presence of a seawater-saturated snow layer results in an increased subsurface conductivity and therefore thickness underestimate. It is very likely that the apparent decrease of the thickness of thick ice (Fig. 7) is actually more a result of increased flooding than of ice bottom melt, because the thick ice is likely to flood during the progression of summer for two reasons. First, as observed at sites 5 and 8, the thick SYI had mostly a negative freeboard. Second, the progression of warming increased the likelihood for flooding taking place either by upward brine motion or by lateral inflow of water along the snow/ice interface through a warming snow layer. The more than week-long continued flooding induced by drilling at site 8 provides an impressive example for the potential flooding that can occur during summer (see above). Unfortunately, we lack specific data on the occurrence of flooding throughout the study period. In contrast, the absence of flooding on SYI in late November and early December despite the widespread occurrence of negative freeboard indicates that SYI ice is largely impermeable during winter, due to cold surface temperatures and the desalination during the preceding summer (Eicken 1998; Haas et al., 2001).

For future EM sea ice measurements, it would be highly desirable to use multi-frequency EM instruments, which might be able to resolve the presence of flooding or gap layers, or even their thickness.

An important result of most ISPOL measurements is the small amount of ice and snow thinning occurring in the western Weddell Sea during December (Figs. 7 and 8; Nicolaus et al., 2006). According to our measurements over the five-week observation period, thinning amounted only to between 0 and $0.4 \mathrm{~m}$, including up to $0.2 \mathrm{~m}$ snow thickness decrease. The snow thinning was largely due to settling and evaporation, with little superimposed ice formation (Nicolaus et al., 2006). Nicolaus (personal communication, 2006) and Launiainen et al. (2007) derive an atmospheric heat flux of $7.9 \mathrm{~W} / \mathrm{m}^{2}$ to explain the observed snow-thickness decrease. The remaining $0-0.15 \mathrm{~m}$ of ice thinning due to bottom melt would require up to $15 \mathrm{~W} / \mathrm{m}^{2}$ of ocean heat flux, in agreement with the range of values measured by McPhee (2008). Note that this value is smaller than other estimates of ocean heat flux in the Weddell Sea (e.g., Martinson and Iannuzzi, 1998). Small thinning rates are also consistent with a slight decrease of surface-water salinity measured by standard CTD casts from board R.V. Polarstern (Absy et al., 2008). With the little observed ice and snow thinning and small freshening of the ocean surface layer, and in the absence of information about lateral melt, it is very hard to compute a closed salt balance.

During ISPOL we have encountered many problems due to insufficient instrumentation and the special circumstances of measurements under summer conditions. Instrumentation issues include the usage of ice coring for example. As ice coring is a destructive method, repeat measurements have to involve coring at different locations. Even within small distances, the lateral variability can be quite high (Eicken et al., 1991), and can be even larger than temporal changes. Therefore, the results shown in Figs. 6 and 9 have to be taken with care. Also, more sensitive thickness measurements would be required to detect very small thickness changes. However, even thickness drilling is prone to problems with lateral variability, as shown with the two ice cores at site 8 (Fig. 6) and ice-core profiles presented by Hellmer et al. (2006) and Tison et al. (2008). As an alternative, we also have tried to use thickness gauges based on the use of heated wires (Perovich et al., 2003). However, as the holes for the heated wires had been drilled in late November and early December, they never froze solid again, and many of the wires could be pulled up without any significant resistance from the ice underside, making detection of the ice/water interface impossible.

Finally, the results of coring of warm ice have to be taken with care. As porosity and permeability increase with warming, considerable amounts of brine can be lost during coring. Therefore, results of salinity and brine volume change presented in Figs. 6 and 9 can actually strongly underestimate the true changes. However, here the results of the non-destructive DC geoelectric and EM sounding measurements can be of particular value if more experience is gained. While the DC measurements are also subjected to variable coupling conditions between electrodes and ice, EM depth sounding provides a contact-less, non-destructive measurement of ice properties. However, as visible from Fig. 11, the sensitivity and calibration stability of currently available instruments is not satisfying either.

\section{Conclusions}

Ice and snow thickness measurements, ice-core analyses, and the interpretation of satellite imagery have revealed 
that the ISPOL floe was composed of a mixture of fragments of different ice types, and that thin and thick FYI and thick SYI were the main ice types. Therefore, the composition of the ISPOL floe reflected nicely its location on the boundary between two distinct bands of FYI and SYI of different origin. Most ice, however, was thick SYI with a thick snow cover.

Although the 5-week long observation period extended over summer solstice and received therefore the maximum possible solar shortwave radiation, only small amounts of thinning were observed. These were largely due to snow thinning by settling and evaporation, with little superimposed ice formation (Nicolaus et al., 2006). The small thinning demonstrates the stability of the perennial sea ice in the western Weddell Sea. With generally high ice concentrations $\geqslant 90 \%$ during the study period (Steer et al., 2008), with the thick snow cover, and with low ocean heat flux (McPhee, 2008), summer melt is minute. This points to the importance of floe break up, reductions in ice concentration, and the resulting absorption of solar radiation in leads for increases in ocean heat flux and subsequent lateral and bottom melt (McPhee, 2008; Steer et al., 2008). Lateral melt unfortunately was not measured during ISPOL at all.

The small amount of ice and snow thinning is also in stark contrast to similar observations in the Arctic, where rapid thinning and extensive melt pond formation are observed even before summer solstice (Eicken et al., 2001, 2004). These differences confirm earlier studies of the general differences between the importance of different components of the surface energy balance in the sea ice zones of the Arctic and Southern Oceans (Andreas and Ackley, 1982; Nicolaus et al., 2006).

A future drift station in the Weddell Sea should therefore begin at the same time as ISPOL, where winter conditions with cold ice and snow were still prevailing in the beginning. However, it should extend for a much longer time until the end of summer in February or March to be able to monitor changes in the regional radiation and energy balance and the likely subsequent accelerated changes of snow and ice thickness. This will reveal new insights into the processes involved in the feedbacks between ice thinning and albedo.

Measurements during ISPOL have also shown the difficulty of observing small changes during summer, which were smaller than the sensitivity and resolution of most methods. Measurements were also hampered by the simultaneous change of several ice properties like thickness and conductivity. Future observations should also be based more on the use of automatic continuous measurements. However, special precautions have to be taken to prevent problems related to strong radiation heating and destructions by the installation of sensors. After these technological challenges have been solved, a repetition and extension of ISPOL will be most desirable to gather observations of melt processes during the complete ablation season.

\section{Acknowledgements}

We are most grateful for field and lab support by A. Batzke and J. Lobach. Cruise leader M. Spindler did a splendid job to accommodate the needs of the various field programs. Without the skidoo shuttle service maintained by the crew of R.V. Polarstern the work would not have been possible. We thank the Alfred Wegener Institute for allowing to stop the ship for 5 weeks to go with the floe. Near-real-time satellite imagery were acquired and transmitted by ESA, NASA, T. Busche and L. Toudal and helped the ship to easily reach its anchoring position and to plan field operations.

\section{References}

Absy, J.M., Schröder, M., Muench, R., Hellmer, H.H., 2008. Early summer thermohaline characteristics and mixing in the western Weddell Sea. Deep-Sea Research II, this issue [doi:10.1016/ j.dsr2.2007.12.023].

Anderson, W.L., 1979. Computer program numerical integration of related Hankel transforms of orders 0 and 1 by adaptive digital filtering. Geophysics 44, 1287-1305.

Andreas, E.L., Ackley, S.F., 1982. On the differences in ablation seasons of Arctic and Antarctic sea ice. Journal of Atmospheric Science 39 (2), 440-447.

Archie, G.E., 1942. The electrical resistivity log as an aid in determining some reservoir characteristics. Transactions of American Institute of Mining, Metallurgical, and Petroleum Engineering 146, 54-62.

Cox, G.F.N., Weeks, W.F., 1983. Equations for determining the gas and brine volumes in sea-ice samples. Journal of Glaciology 29, 306-316.

Dieckmann, G.S., Haas, C., Schröder; M., 2007. Ice Station POLarstern (ISPOL). In: El Naggar, S., Dieckmann, G.S., Haas, C., Schröder, M., Spindler, M. (Eds.), The Expeditions ANTARKTIS-XXII/1 and XXII/2 of the Research Vessel Polarstern in 2004/2005. Reports on Polar and Marine Research, 551, 37-259.

Eicken, H., 1998. Deriving modes and rates of ice growth in the Weddell Sea from microstructural, salinity and stable-isotope data. In: Jeffries, M.O. (Ed.), Antarctic Sea ice: Physical Processes. Interactions and Variability. Antarctic Research Series, Vol. 74. American Geophysical Union, Washington D.C., USA, pp. 89-122.

Eicken, H., Lange, M.A., Dieckmann, G.S., 1991. Spatial variability of sea-ice properties in the northwestern Weddell Sea. Journal of Geophysical Research 96, 10603-10615.

Eicken, H., Lange, M.A., Hubberten, H.W., Wadhams, P., 1994. Characteristics and distribution patterns of snow and meteoric ice in the Weddell Sea and their contribution to the mass balance of sea ice. Annales Geophysicae 12, 80-93.

Eicken, H., Tucker III., W.B., Perovich, D.K., 2001. Indirect measurements of the mass balance of summer Arctic sea ice with an elotromagnetic induction technique. Annals of Glaciology 33, 194-200.

Eicken, H., Grenfell, T.C., Perovich, D.K., Richter-Menge, J.A., Frey, K., 2004. Hydraulic controls of summer Arctic pack ice albedo. Journal of Geophysical Research 109 (C08007).

Haas, C., Gerland, S., Eicken, H., Miller, H., 1997. Comparison of sea-ice thickness measurements under summer and winter conditions in the Arctic using a small electromagnetic induction device. Geophysics 62, 749-757.

Haas, C., Thomas, D.N., Bareiss, J., 2001. Surface properties and processes of perennial Antarctic sea ice in summer. Journal of Glaciology 47 (159), 613-625.

Haas, C., Hendricks, S., Doble, M., 2006. Comparison of the sea ice thickness distribution in the Lincoln Sea and adjacent Arctic Ocean in 2004 and 2005. Annals of Glaciology 44, 247-252. 
Haas, C., Jochmann, P., 2003. Continuous EM and ULS thickness profiling in support of ice force measurements. In: Proceedings of the 17th International Conference on Port and Ocean Engineering under Arctic Conditions. Department of Civil and Transport Engineering, Norwegian University of Science and Technology NTNU, Trondheim, Norway, pp. 849-856.

Heil, P., Hutchings, J.K., Worby, A.P., Johansson, M., Launiainen, J., Haas, C., Hibler III, W.D., 2008. Tidal forcing on sea-ice drift and deformation in the western Weddell Sea in early austral summer, 2004. Deep-Sea Research II, this issue [doi:10.1016/j.dsr2.2007.12.026].

Hellmer, H.H., Dieckmann, G.S., Haas, C., Schröder, M., 2006. Sea ice feedbacks observed in western Weddell Sea. EOS, Transactions, American Geophysical Union 87 (18), 173-179.

Hellmer, H.H., Schröder, M., Haas, C., Dieckmann, G.S., Spindler, M., 2008. The ISPOL drift experiment. Deep-Sea Research II, this issue [doi:10.1016/j.dsr2.2008.01.001].

Kovacs, A., Morey, R.M., 1991. Sounding sea-ice thickness using a portable electromagnetic induction instrument. Geophysics 56, 1992-1998.

Lange, M.A., 1988. Basic properties of Antarctic sea ice as revealed by textural analysis of ice cores. Annals of Glaciology 10, 95-101.

Lange, M.A., Eicken, H., 1991. The sea ice thickness distribution in the northwestern Weddell Sea. Journal of Geophysical Research 96 (C3), 4821-4837.

Launiainen, J., Johansson, M., Kosloff, P., 2007. Meteorological conditions and surface fluxes and energy balance during ISPOL. In: El Naggar, S., Dieckmann, G.S., Haas, C., Schröder, M., Spindler, M. (Ed.), The Expeditions ANTARKTIS-XXII/1 and XXII/2 of the Research Vessel Polarstern in 2004/2005. Reports on Polar and Marine Research 551, 53-66.

Leppäranta, M., Manninen, T., 1988. The brine and gas content of sea ice with attention to low salinities and high temperatures. Finnish Institute of Marine Research, Internal Report 2.

Lines, L.R., Treitel, S., 1984. Tutorial: a review of least-squares inversion and its application to geophysical problems. Geophysical Prospecting 32, 159-186.

Loke M.H., 2001. RES1D ver. 1.00a Beta. 1-D Resistivity, IP and SIP Modeling. 〈http://www.geoelectrical.com 〉 freeware.

Lytle, V.I., Ackley, S.F., 1996. Heat flux through sea ice in the western Weddell Sea: convective and conductive transfer processes. Journal of Geophysical Research 101 (C4), 8853-8868.

Martinson, D.G., Iannuzzi, R.A., 1998. Antarctic ocean-ice interaction: implications from ocean bulk property distributions in the Weddell Gyre. In: Jeffries, M.O. (Ed.), Antarctic Sea ice: Physical Processes, Interactions and Variability. Antarctic Research Series, vol. 74. American Geophysical Union, Washington, DC, USA, pp. 243-271.

McNeill, J.D., 1980. Electromagnetic terrain conductivity measurement at low induction numbers. Technical Note TN-6, Geonics, Mississauga, ON, Canada.

McPhee, M.G., 2008. Physics of early summer ice/ocean exchanges in the western Weddell Sea during ISPOL. Deep-Sea Research II, this issue [doi:10.1016/j.dsr2.2007.12.022].
Nicolaus, M., Haas, C., Bareiss, J., Willmes, S., 2006. A model study of differences of snow thinning on Arctic and Antarctic first-year sea ice during spring and summer. Annals of Glaciology 44, $146-153$.

Papadimitriou, S., Thomas, D.N., Kennedy, H., Kuosa, H., Dieckmann, G.S., 2007. Biogeochemical composition of natural sea ice brines from the Weddell Sea during early austral summer. Limnology and Oceanography 52, 1809-1823.

Perovich, D.K., Grenfell, T.C., Richter-Menge, J.A., Light, B., Tucker III., W.B., Eicken, H., 2003. Thin and thinner: ice mass balance measurements during SHEBA. Journal of Geophysical Research 108 (C3).

Pfaffling, A., Haas, C., Reid, J.E., 2007. A direct helicopter EM sea ice thickness inversion, assessed with synthetic and field data. Geophysics 72, F127-F137.

Reid, J., Pfaffling, A., Vrbancich, J., 2006a. Airborne electromagnetic footprints in one-dimensional earths. Geophysics 71 (2), G63-G72.

Reid, J.E., Pfaffling, A., Worby, A.P., Bishop, J.R., 2006b. In-situ measurements of the direct-current conductivity of Antarctic sea ice: implications for airborne electromagnetic sounding of sea-ice thickness. Annals of Glaciology 44, 217-223.

Steer, A., Worby, A., Heil, P., 2008.Observed changes in sea ice floe size distribution during early summer in the western Weddell Sea. Deep-Sea Research II, this issue [doi:10.1016/j.dsr2.2007.12.016].

Stogryn, A., Desargant, G.J., 1985. The dielectric properties of brine in sea ice at microwave frequencies. IEEE Transaction on Antennas and Propagation AP-33, 523-532.

Strass, V.H., Fahrbach, E., 1998. Temporal and regional variation of sea ice draft and coverage in the Weddell Sea obtained from Upward Looking Sonars. In: Jeffries, M.O. (Ed.), Antarctic Sea Ice: Physical Processes, Interactions and Variability. Antarctic Research Series, vol. 74. American Geophysical Union, Washington, DC, USA, pp. 123-140.

Telford, W.M., Geldart, L.P., Sheriff, R.E., 1990. Applied Geophysics. Cambridge University Press, 790pp.

Thomas, D.N., Lara, R.J., Haas, C., Schnack-Schiel, S.B., Dieckmann, G.S., Kattner, G., Noethig, E.-M., Mizdalski, E., 1998. Biological soup within decaying summer sea ice in the Amundsen Sea, Antarctica. In: Lizotte, M.P., Arrigo, K.R. (Eds.), Antarctic Sea Ice Biological Processes, Interactions and Variability. Antarctic Research Series, vol. 73. American Geophysical Union, Washington, DC, USA, pp. 161-172.

Tison, J.-L., Worby, A., Delille, B., Brabant, F., Papadimitriou, S., Thomas, D., de Jong, J., Lannuzel, D., Haas, C., 2008. Temporal evolution of decaying summer first-year sea ice in the western Weddell Sea, Antarctica. Deep-Sea Research II, this issue [doi:10.1016/ j.dsr2.2007.12.021].

Willmes, S., Bareiss, J., Haas, C., Nicolaus, M., 2006. The importance of diurnal processes for the seasonal cycle of sea-ice microwave brightness temperatures during early summer in the Weddell Sea. Annals of Glaciology 44, 297-302. 